\title{
Alteration of NADH Succinate Dehydrogenase Activity and Redox Status By Different Solvent Fractions of Antiaris Africana in the Brain of Rats Exposed To Rotenone
}

\author{
Omotayo B Ilesanmi ${ }^{1 *}$, Rofiat Adewunmi ${ }^{1}$, Alawode T Taiwo ${ }^{2}$, Kayode C Komolafe ${ }^{3}$, Temitope T Odewale, Afolabi \\ C Akinmoladun ${ }^{1}$, Tolulope M Olaleye ${ }^{1}$ and Akintunde A Akindahunsi ${ }^{1}$
}

${ }^{1}$ Department of Biochemistry, School of Sciences, Nigeria

${ }^{2}$ Department of Chemistry, Faculty of Science, Nigeria

${ }^{3}$ Institute of Biophysics, Chinese academy of sciences, China

Received: 眥 January 04, 2019; Published: 阱January 17, 2019

*Corresponding author: Omotayo B Ilesanmi, Department of Biochemistry, School of Sciences, Nigeria

\begin{abstract}
Rotenone is a mitochondria toxin, that exert its effect by free radical generation and inhibiting the activity of complex I, leading to mitochondria damage. NADH-succinate dehydrogenase is a mitochondria enzyme used as a biomarker of mitochondria integrity. Antiaris africana is a plant in Nigeria, generally used for the treatment of nervous disorders. We have already reported the neuroprotective effect of crude extract of $A$. africana on rotenone toxicity. Thus, this study was aimed at evaluating the protective effect of different solvent fractions of Antiaris africana against rotenone induced damage to mitochondria fraction in the cerebrocortex region of the brain. crude extract of $A$. africana was partitioned into n-hexane (HFA), methanol (MFA) and dichloromethane (DFA). Each fraction was evaluated against rotenone-induced inhibition of NADH succinate-dehydrogenase activity, lipid peroxidation (LPO), protein carbonyl (PC), depletion of reduced glutathione (GSH) and increased monoamine oxidase (MAO) activity in vitro. Solvent fractions treatment leads to significant reduction in the level of LPO, PC and activity of MAO at P<0.05. The rotenone-induced inhibition of mitochondria electron transport system viz inhibition of NADH succinate dehydrogenase was reversed by all fractions of $A$. africana while the level of GSH was significantly increased $(\mathrm{P}<0.001)$. The result showed that all the fractions of $A$. africana, showed neuroprotective activity at varying degree, suggesting they each solvent fraction may possess bioactive phytochemicals that can be isolated for treatment of some neurodegenerative diseases.
\end{abstract}

Keywords: Antiaris Africana; Rotenone; Mitochondria; Oxidative Stress; Neurodegenerative Diseases

Abbreviations: DFA: Dichloromethane; LPO: lipid peroxidation, PC: Protein Carbonyl, GSH: Glutathione; MAO: Monoamine Oxidase; ROS: Reactive Oxygen Species; OS: Oxidative Stress; HFA: n-Hexane Fraction; MFA: Methanol Fraction; DFA: Dichloromethane Fraction

\section{Introduction}

Excessive reactive oxygen species (ROS) production can outweigh cellular antioxidant defenses leading to oxidative stress (OS). This process has been consistently linked to age-related neurodegenerative diseases Recently, research has focused on the role of OS in neurodegenerative disorders Oliveira et al. [1]. Some of the features of brain include high dependence on oxygen for all its metabolic activities, high concentration of oxidizable fatty acids,

reduce ability of cell regeneration and low levels of antioxidant enzymes Kumar et al. [2]. One of the key organelles involved in OS is the mitochondria, it is central to most of the biological function linked to oxidative metabolism, such as energy conversion for ATP synthesis, ion homeostasis, fatty acid biosynthesis, iron sulfur cluster biogenesis, calcium storage, and importantly the cell death pathways Spinazzi et al. [3]. 
Thus damage to this organelle in the brain leads to cumulative oxidative stress, disrupted mitochondrial respiration, and mitochondrial damage may promote cell death and degeneration in most of the diseases linked to brain and nervous disorders, such as, Alzheimer's disease, Parkinson's disease and Huntington disease Halliwell et al. [4,5]. Some of the commonly used chemicals used as pesticides, component of domestic and laboratory reagents has been reported to affect motor neurons via mitochondria destruction culminating in cell death. Some of these chemicals have been used to model various forms of neurological disorders in the development of novel drugs in treatment and management of neurodegenerative diseases Duty et al. [6].

Pharmacological approach to resisting OS and maintain mitochondria integrity seems to be a promising therapeutic strategy to counter neurodegenerative disorders. In this context, studies have focused on the potential use of natural compounds in a variety of conditions associated with OS, with special emphasis on medicinal herbs (and/or their metabolites) that are commonly used by herbalists Akinmoladun et al. [7-9]. Drugs that specifically target this process could be useful in the treatment of these diseases. Antiaris africana is a plant found in various parts of Nigeria and West Africa. It is commonly called Ooro, Oriro or ako Iroko in the South West part of Nigeria; Farin Loko in the North; and Ojianwu in the South East Ilesanmi et al. [10]. A. africana is a large attractive deciduous timber tree, which grows up to $120 \mathrm{ft}$ (30-40m) high and attain full size within 20 years Sosef et al. [11]. It has a grey bark on slashing exudes a watery latex which soon darkens to the colour of milky tea. Its ripe fruits are red or orange Olofinbaba [12]. The plant is utilized traditionally in ethno-medicine for epilepsy, lumbago, skin irritant, rheumatic and respiratory infections, stomach pains, purgative, nervous disorders Odugbemi [13]. The leaves and root are also used to treat mental illnesses. Seed, leaves and bark are used as an astringent and the seeds as an antidysenteric. However, review of different research publication showed some lacunae in the possible mechanism of protection of $A$. africana against brain degeneration. Therefore, this research was conducted to provide answer to this gap.

\section{Materials and Methods}

\section{Chemicals}

All chemicals and reagents used were of analytical grade and the water used was glass distilled. Randox diagnostic kits, used to assay for total protein concentration were purchased from Randox laboratory Ltd, United Kingdom.

\section{Plant Collection, Preparation of Extract and Partition}

Crude extract was prepared according to the method described by Ilesanmi et al. [14]. Partitioning of crude extract was carried out with n-hexane, dichloromethane and methane (based on their polarity) according to standard laboratory method. Each fractions collected was concentrated in a rotary evaporator to obtain n-hexane fraction (HFA), methanol fraction (MFA) and dichloromethane fraction (DFA) of A. africana, which were used for analysis.

\section{Animal Handling and Care}

Male wistar rats $(200 \pm 30) \mathrm{g}$, bred and housed in the primate colony of the animal house of the Department of Animal Production and Health of Federal University of Technology, Akure. They were maintained in laboratory conditions under natural light, dark cycle and fed with standard rat chow and water ad libitum. Animals were handled and used in accordance with the international guide for the care and use of laboratory animals.

\section{Tissue Preparation}

Male wistar rats were sacrificed, the brain was rapidly excised and the blood and external vessels were carefully removed. The cerebrocortex region was carefully separated from the brain, rinsed with $0.32 \mathrm{M}$ sucrose, weighed and homogenized using $0.1 \mathrm{M}$ phosphate buffer saline (PBS) at $\mathrm{P}^{\mathrm{H}} 7.4$ in a manual glass-teflon homogeniser on ice to obtain $10 \% \mathrm{w} / \mathrm{v}$ homogenate. Mitochondrial suspensions were prepared by differential centrifugation according to the modified method of Maharaj et al. [15]. Briefly, rat brain homogenate was centrifuged at $600 \mathrm{~g}$ for 5 minutes, and the supernatant was reconstituted in $0.25 \mathrm{M}$ sucrose before centrifuging at $15,000 \mathrm{~g}$ for 30 minutes at $2^{\circ} \mathrm{C}$. The microsome-plussoluble fraction was further centrifuged at $15,000 \mathrm{~g}$ for 1 hour at $2^{\circ} \mathrm{C}$. The microsomal pellet obtained was rinsed and suspended in sucrose-phosphate-EDTA medium and centrifuged at 25,000 g for 30 minutes at $2^{\circ} \mathrm{C}$, and the pellet obtained was resuspended in sucrose-phosphate-EDTA medium to reconstitute to the original 20 $\mathrm{x}$ homogenate equivalent for biochemical assays.

\section{Experimental Design}

The experiment was divided into three groups: positive control group, consisted of mitochondria suspension and rotenone $(0.1 \mathrm{M})$; negative control group consisted of mitochondria suspension and distilled water; and treated group consisted of mitochondria suspension, extracts and rotenone

\section{Preparation of Reaction Mixture Via In-Vitro Induction of Mitochondrial Damage}

The cerebrocortex mitochondrial suspension was added to the following reagents; sodium phosphate buffer $\left(0.1 \mathrm{M}\right.$ and $\mathrm{P}^{\mathrm{H}}$ 7.4) and sucrose EDTA $(0.25 \mathrm{M})$ before incubating with varying concentrations of the different fractions of A. africana $(50-1000 \mu \mathrm{g} /$ $\mathrm{ml}$ ) with or without rotenone for $3 \mathrm{~h}$ at $37^{\circ} \mathrm{C}$ in a temperaturecontrolled water bath. The positive control contained all the reaction mixture except the fractions and the negative control contains all the reaction mixture apart from the toxicant and the fractions. The stock and working solutions were prepared in such a way that the same volume was added in the supernatant of cerebrocortex for incubation.

\section{Biological Oxidation Assay}

This activity was carried out based on the ability to reduce p-iodonitro tetrazolium violet, as described by Penington [16]. The reaction mixture was incubated with phosphate buffer $(50 \mathrm{mM})$, sodium succinate $(0.01 \mathrm{M})$ and p-iodonitro tetrazolium (INT) $(2.5 \mu \mathrm{g} / \mathrm{ml})$ at room temperature for 10 minutes. After incubation, 
TCA (10\%) and ethylacetate/ethanol/TCA (5:5:1, v: v: w) was added. Absorbance was read at 490nm. Results expressed as nmol of INT/ mg protein.

\section{Estimation of Reduced Glutathione (GSH) Level}

Reduced GSH content was determined according to Jollow et al. [17]. Distilled water and TCA (1\%) were added to the reaction mixture and incubated for 20 minutes at $25^{\circ} \mathrm{C}$, and the mixture was centrifuged at $3500 \mathrm{~g}$ for 5 minutes. Ellman's reagent was added to the clear supernatant and absorbance was read $412 \mathrm{~nm}$. The concentration of GSH was determined from standard curve.

\section{Lipid Peroxidation Inhibitory Activity}

The lipid peroxidation inhibitory activity was evaluated by measuring the formation of TBA reactive substances (TBARS) according to the method of Okhawa et al. [18]. To the reaction mixture, Tris-KCl buffer (0.15 M), TCA (30\%) and TBA (0.75\%) were added. The mixture was incubated for 30 minutes in a control water bath at $85^{\circ} \mathrm{C}$. This was then cooled on ice and centrifuged at $3000 \mathrm{~g}$ for 3 minutes. The absorbance of the clear supernatant was read at $532 \mathrm{~nm}$. The MDA level was calculated according to the method of Adam Vizi et al. [19]. Lipid peroxidation in units/mg protein was computed with a molar extinction coefficient of $1.56 \times 105 \mathrm{M}-1 \mathrm{Cm}^{-1}$.

\section{Determination of Protein Carbonyl}

Principle: Protein carbonyl levels in the samples were quantified according to the method described by Floor et al. [20]. This is based on the reaction of DNPH with protein carbonyl contents to produce the corresponding hydrazone. The reaction mixture was allowed to react with $10 \mathrm{mM}$ DNPH in $2 \mathrm{M} \mathrm{HCl}$ for $1 \mathrm{~h}$ at room temperature and precipitated with $20 \%$ TCA. The pellet was washed thrice with acetone and dissolved in $2 \mathrm{mM}$ Tris- $\mathrm{HCl}$ buffer $\left(\mathrm{P}^{\mathrm{H}} 7.4\right.$, containing $2 \%$ SDS). The mixture was centrifuged at $1600 \mathrm{~g}$ for $5 \mathrm{~min}$ to remove any trace of insoluble material. The carbonyl content was measured spectrophotometrically at $340 \mathrm{~nm}$. The results were expressed as nmol DNPH incorporated/mg protein based on the molar extinction coefficient of $2.1 \times 104 \mathrm{M}^{-1} \mathrm{~cm}^{-1}$.

\section{Determination of Monoamine Oxidase Activity (MA0)}

MAO was measured by using the method developed by Holt et al. [21] and described by Chaudhary et al. [22]. Briefly, the reaction mixture was incubated with $0.1 \mathrm{M}$ Benzylamine hydrochloride (BAHC) and $0.1 \mathrm{M}$ phosphate buffer at room temperature for $30 \mathrm{~min}$. It was followed by the addition of $10 \%$ perchloric acid, and the mixture was centrifuged for $10 \mathrm{~min}$ at $1500 \mathrm{~g}$. The enzyme activity was calculated as nmol BAHC hydrolysed/min/mg protein using a molar extinction coefficient of $7.6925 \mathrm{M}^{-1} \mathrm{~cm}^{-1} @ 280 \mathrm{~nm}$.

Activity of monoamine oxidase (BAHC hydrolysed/min $/ \mathrm{mg}$ protein $)=\underline{\Delta a b s \times \text { vol of mixture }}$

$$
(\text { E280 } \mathrm{nm} \times \Delta \text { time })
$$

\section{Statistical Analysis}

SPSS 16.0 software was applied to analyse experimental data and the result were expressed as mean \pm SD. All data were evaluated with analysis of variance (one way ANOVA) following by Duncan's test (equal variance assumed) for post hoc multiple comparison and $\mathrm{P}<0.005$ indicate that the difference was statistically significant. Table 1.

Table 1: Inhibition of potassium cyanide-induced increase in monoamine oxidase activity with different fractions of $A$. africana in rat cortex.

\begin{tabular}{|c|c|c|c|}
\hline \multicolumn{4}{|c|}{ Monoamine Oxidase Activity ( $\mu$ moles BAHC Hydrolyzed/min/mg Protein) } \\
\hline Concentration $(\mu \mathrm{g} / \mathrm{ml})$ & HFA & MFA & \\
\hline Control & 0.00 & & \\
\hline Untreated & $20.84 \pm 0.528^{*}$ & & $7.92 \pm 0.037 \#$ \\
\hline 50 & $10.24 \pm 0.034 \#$ & $7.59 \pm 0.018 \#$ & $4.42 \pm 0.013 \#$ \\
\hline 100 & $5.74 \pm 0.034 \#$ & $5.25 \pm 0.030 \#$ & $3.95 \pm 0.024 \#$ \\
\hline 200 & $5.89 \pm 0.044 \#$ & $5.16 \pm 0.003 \#$ & $2.63 \pm 0.043 \#$ \\
\hline 400 & $9.40 \pm 0.020 \#$ & $4.71 \pm 0.012 \#$ & $1.50 \pm 0.023 \#$ \\
\hline 600 & $5.79 \pm 0.015 \#$ & $4.70 \pm 0.022 \#$ & $1.46 \pm 0.003 \#$ \\
\hline 800 & $7.49 \pm 0.003 \#$ & $3.86 \pm 0.013 \#$ & $1.12 \pm 0.016 \#$ \\
\hline
\end{tabular}

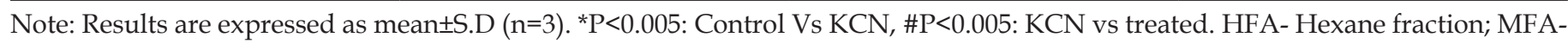
Methanol fraction; DFA-Dichloromethane fraction.

\section{Results and Discussion}

Herbal products contain complicated mixtures of organic chemicals, which may include fatty acids, sterols, alkaloids, flavonoids, glycosides, saponins, tannins, terpenes. They are becoming a drug of choice in the treatment of diseases due to their lower toxicity and affordability Akinmoladun et al. [23]. Neurodegenerative disease is becoming a focus for the utilization of natural products in prevention and treatment Ilesanmi et al. [10].
Previous study on A. africana leaves has shown the plant to possess a strong antioxidant, anti-inflammatory and antitumor activities Ilesanmi et al. [14], Kuete et al. [24,25], reported the antioxidant and antibacterial activities of the flavonoid-rich fraction. Results from this experiment showed that all the solvents fraction were effective against rotenone neurotoxicity. Figure 1 shows the effect of different fractions of $A$. africana on rotenone -induced inhibition of mitochondrial electron transport system utilizing succinate in the cerebrocortex. Rotenone caused a significant inhibition of NSD 
activities $(\mathrm{P}<0.05)$ as compared to the control group. The inhibitory effect of rotenone was significantly ameliorated by all the solvent fractions of $A$. africana in a concentration dependent pattern. All solvent fractions were effective at the lowest concentration $(50 \mu \mathrm{l})$. Overall, HFA was generally was more potent as compared to other fractions activity of NSD has being shown to be altered by the presence of mitochondria toxin, thus, it is often used as a biomarker of mitochondria damage in identifying plants and natural products that can protect against mitochondria injury Anacharis et al. [26]. The present investigation revealed that all the solvent fractions of A. africana reversed the inhibitory effect of rotenone in cerebrocortex tissue.

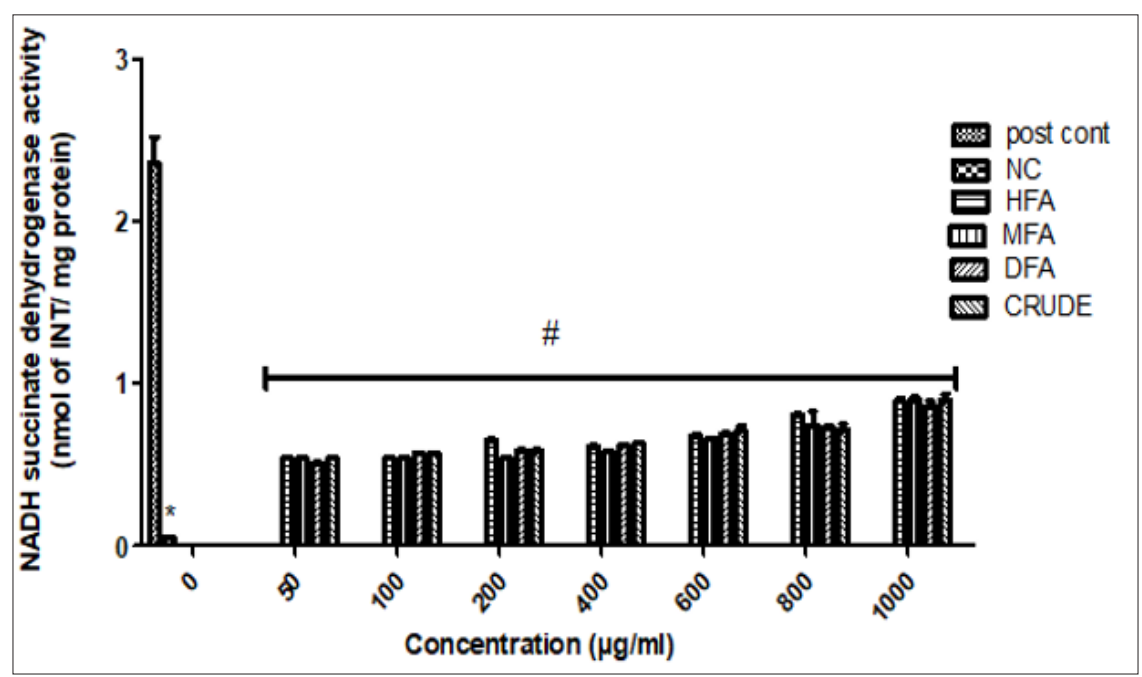

Note: Values are expressed as mean \pm S.D $(n=3) .{ }^{*} \mathrm{P}<0.005$ : post contVs rotenone, $\# \mathrm{P}<0.005$.

Figure 1: Effect of different fractions of A. africana on rotenone -induced inhibition of mitochondrial electron transport system utilizing succinate in the cerebellum.

It is well known that rotenone is a Complex-I inhibitor of the electron transport chain, making it a mitochondria toxin. To ascertain the extent of damage, NSD, a known marker of mitochondria injury Ajith et al. [27] was evaluated. Our results showed that rotenone significantly inhibited the activity of NSD. All the solvent fractions showed a concentration dependent increase in NSD activities, however, there was no significant difference between the different solvent fraction used. Gautier et al. [28] reported that rotenone caused a significant stress on the activity of mitochondria by inhibiting the activity of NSD., this was also corroborated by Kuznetsov et al. [29]. Mitochondria dysfunction has been implicated in the etiology of several neurodegenerative diseases, such as PD and AD Mandemakers et al. [30]. Thus the ability of all the solvent fractions to protect against rotenone damage shows a probably mechanism of neuroprotective properties.

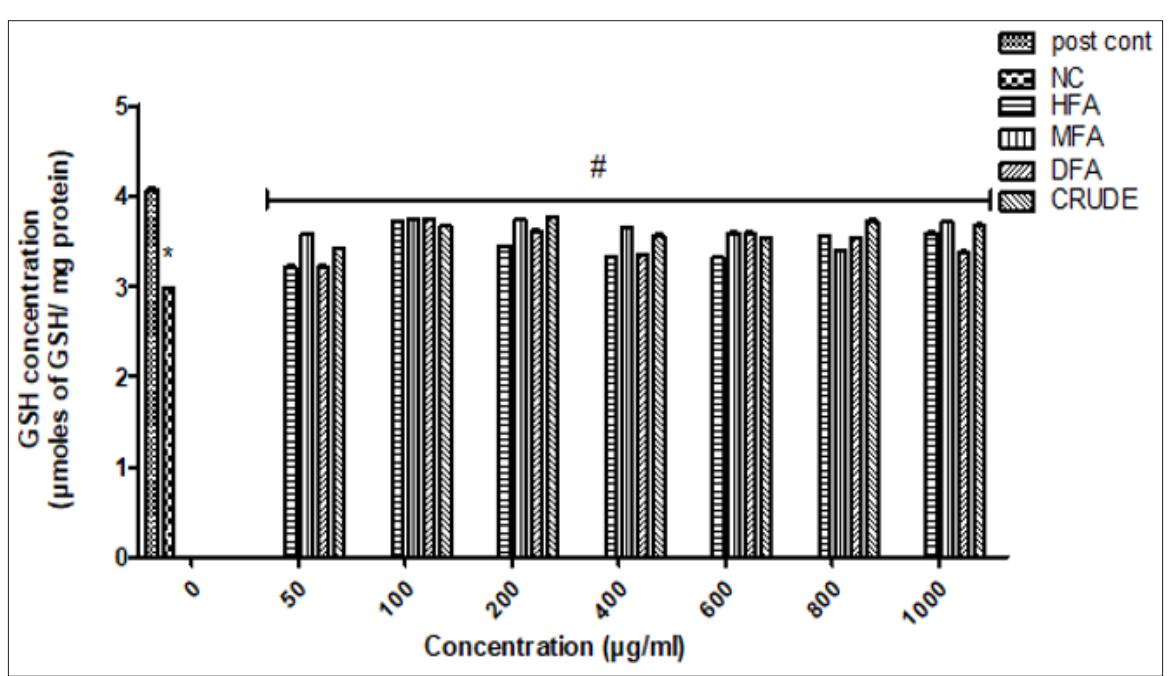

Note: Values are expressed as mean \pm S.D $(n=3)$. ${ }^{*}<0.005$ : post contVs rotenone, $\# \mathrm{P}<0.005$.

Figure 2: Ameliorative effect of different fractions of A. africana on concentration of reduced glutathione (GSH) in rotenone neurotoxicity in rat cerebellum. 
Figure 2 shows the ameliorative effect of different solvent fractions of A. africana on the level of reduced glutathione (GSH) in rotenone neurotoxicity in rat cerebrocortex. Glutathione, a tripeptide is the major defense against reactive species in the brain Aoyama et al. [31,32]. Rotenone significantly deplete GSH level in the cerebrocortex $(\mathrm{P}<0.05)$, reflecting an imbalance in the redox status in the cerebrocortex. This might be linked to electron leakage due to mitochondria damage, causing an increased generation of reactive species Kuznetsov et al. [29], thus outweighing the concentration of GSH in the cerebrocortex Abdel Salam et al. [32]. At lower concentration, $(50 \mu \mathrm{g} / \mathrm{ml})$, HFA, DFA, MFA and CFA showed a $21 \%, 21 \%, 12 \%$ and $16 \%$ increase in GSH level respectively as compared to untreated group. The antioxidant activities of all the solvent fraction can be linked to the abundance of several bioactive phytochemicals present in A. Africana Ilesanmi et al. [14].

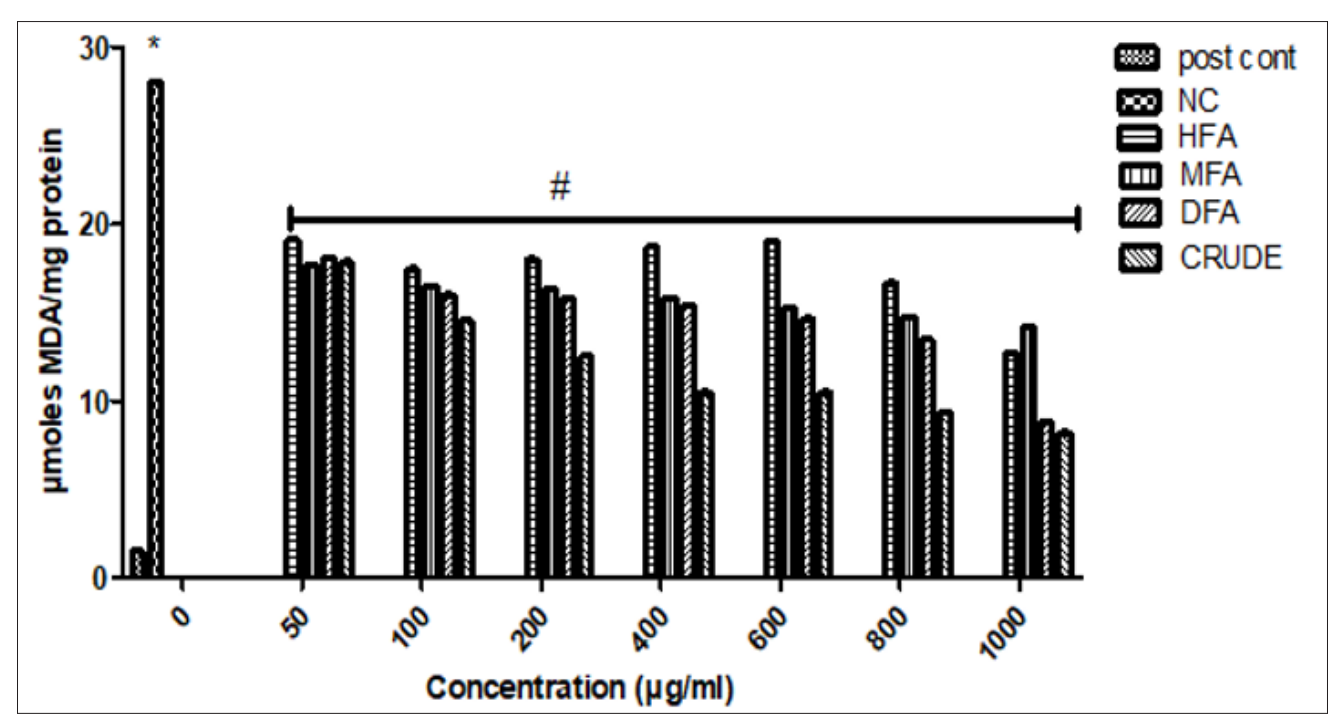

Note: Values are expressed as mean \pm S.D $(n=3)$. ${ }^{*}<<0.005$ : post contVs rotenone, $\# \mathrm{P}<0.005$.

Figure 3: Effect of different fractions of A. africana on rotenone-induced lipid peroxidation in rat cerebellum.

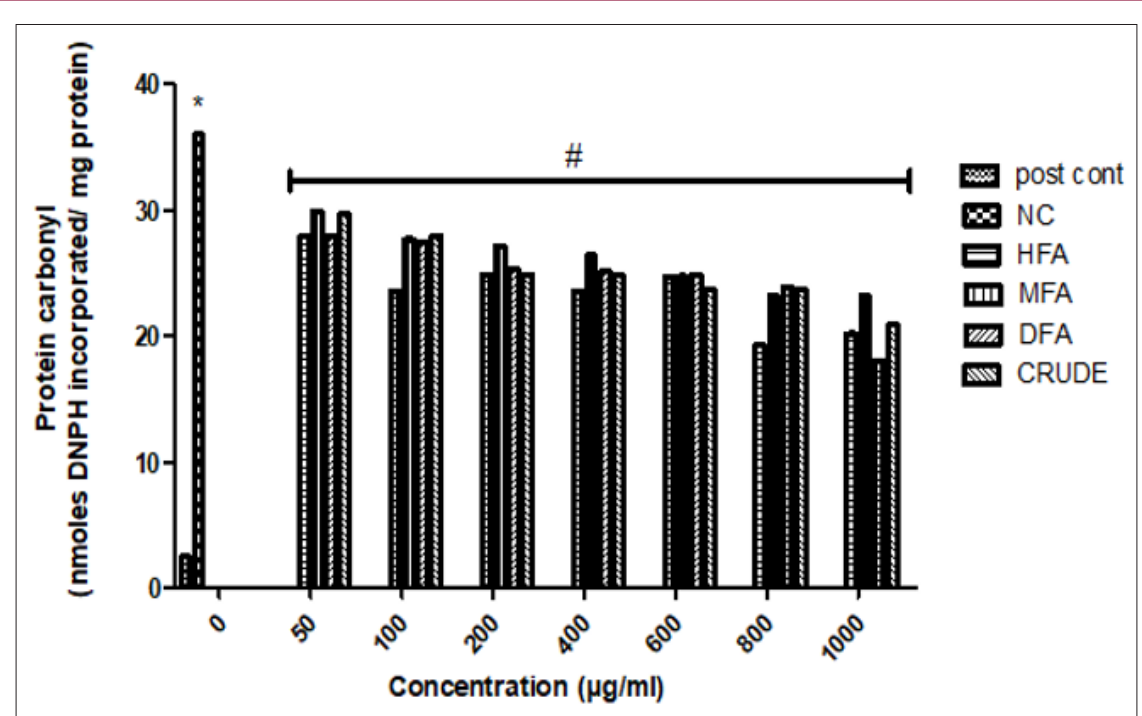

Note: Values are expressed as mean $\pm S . D(n=3)$. ${ }^{*}<0.005$ : post contVs rotenone, $\# \mathrm{P}<0.005$

Figure 4: Effect of different fractions of A. africana on rotenone-induced protein carbonyl formation in rat cerebellum.

Rotenone causes a significant increase in oxidized macromolecules such as lipids and proteins as observed in increase concentration of MA and PC. The abundance of polyunsaturated fatty acids in the brain makes them highly susceptible to oxidative damage. The increased MDA and PC level as a result of rotenone assault can be linked to the possible generation of reactive species, which react with functional lipids and proteins, causing loss of function. This increased can be as a result of released of electron form the mitochondria due to the inhibition of NSD and other ETC enzymes Anacharis et al. [26] This electron leakage causes a significant increase in ROS and RNS Muralidhara et al. [33]. It is the ROS/RNS that reacts with lipids, functional proteins and enzymes, thus altering their physiological functions. All the solvent fractions showed a mild decrease in MDA and PC level as compared 
to the untreated group. Some of the major biomarkers of oxidative damage are oxidized lipids (LPO) and protein carbonyl (PC). They have both been reported to be highly elevated in patients suffering from neurodegenerative diseases Virgilio et al. [34]. Figures 3 \& 4 shows the effects of different fractions of A. africana on rotenoneinduced lipid peroxidation and protein carbonyl formation in rat cerebellum.

The low levels of MDA and PC observed in cerebrocortex exposed to different solvent fractions of $A$. africana in this study clearly suggest its efficacy to probably slow the reaction of rotenone and the reactive species generated with functional lipid and protein in the brain. Overall, CFA showed the best activity as compared to the other fractions at $400 \mu \mathrm{g} / \mathrm{ml}$. This also reflects the antioxidant properties of $A$. africana. Monoamine oxidase is a flavoenzyme that oxidized dopamine, an important hormone that is depleted in neurodegenerative diseases such as PD (sometimes referred to as dopaminergic disorders). Its activity has been shown to reduce the level of dopamine in brain cells Niedzielska et al. [35].

Rotenone causes a significant increase in MAO activity, which is not surprising as rotenone has been reported to reduce the concentration of dopamine by several mechanisms, including activation of MAO, which also causes a further increase in hydrogen peroxide, an important ROS that damages brain cells through oxidation of functional macromolecules such as DNA, protein and lipids Hirayama et al. [36, 34]. all the solvent fractions showed a mild decrease inhibition of MAO activity as compared to the untreated group. MAO inhibitors have been looked at as a potential drug for the management of $\mathrm{PD}$, there has been report that the inhibition of MAO activity can reduce or prevent the formation of alpha synuclein, a major protein found in the brain of PD patient Niedzielska et al. [35]. While several phytochemicals in the class of flavonoids, phenol and alkaloids has been reported to inhibit MAO Popa Wagner et al. [37], their presence in A. africana Ilesanmi et al. $[10,14]$ can contribute to its usage in the treatment of nervous disorders.

\section{Conclusion}

The results presented here suggest that A. africana fractions were able to mitigate the oxidative assault of rotenone in the cerebellum as observed in the above results with varying degree via antioxidant mechanisms. The neuroprotective effects of $A$. africana in this study suggest that it may be a promising therapy for neuronal damage.

\section{References}

1. De Oliveira DM, RMF Lima, RS El Bacha (2012) Brain rust: Recent discoveries on the role of oxidative stress in neurodegenerative diseases. Nutritional Neuroscience 15(3): 94-102.

2. Kumar GP, F Khanum (2012) Neuroprotective potential of phytochemicals. Pharmacognosy Reviews. 6(12): 81-90.

3. Spinazzi M, A Casarin, V Pertegato, L Salviati, C Angelini (2012) Assessment of mitochondrial respiratory chain enzymatic activities on tissues and cultured cells. Nature protocols 7(6):1235-1246.

4. Halliwell B (2006) Oxidative stress and neurodegeneration: where are we now? Journal Neurochemistry 97(6): 1634-1658.
5. Poon HF, HM Shepherd, TT Reed, Calabrese V, Stella AM, et al. (2006) Proteomics analysis provides insight into caloric restriction mediated oxidation and expression of brain proteins associated with age-related impaired cellular processes: mitochondrial dysfunction, glutamate dysregulation and impaired protein synthesis. Neurobiology of Aging 27(7): 1020-1034.

6. Duty S, P Jenner (2011) Animal models of Parkinson's disease: a source of novel treatments and clues to the cause of the disease. British Journal of Pharmacology 164(4): 1357-1391.

7. Akinmoladun AC, Ibukun EO, Afor E, Obuotor E M, Farombi EO (2007) Phytochemical constituent and antioxidant activity ofextract from the leaves of Ocimum gratissimum. Scientific Research and Essay 2(5): 163166.

8. Carey AN, DR Fisher, Joseph JA, Shukitt Hale B (2013) The ability of walnut extract and fatty acids to protect against the deleterious effects of oxidative stress and inflammation in hippocampal cells. Nutritional Neuroscience 16(1): 13-20.

9. Hosamani R, G Krishna, Muralidhara (2014) Standardized Bacopa monnieri extract ameliorates acute paraquat-induced oxidative stress and neurotoxicity in prepubertal mice brain. Nutrition Neuroscience 19(10): 437-446.

10. Ilesanmi OB, AC Akinmoladun, OS Olayeriju, IO Saliu, MT Olaleye et al. (2017) Modulation of key biochemical markers relevant to stroke by Antiaris africana leaf extract following cerebral ischemia/reperfusion injury. Afr J Tradit Complement Altern Med 14 (4): 253-264.

11. Sosef MSM, LT Hong, S Prawirohatmodjo (1998) Timber trees: lesser known species. Backhuys Publishers, Leiden, 64-69.

12. Olofinboba MO (2002) Sap stain in A.africana, an economically important tropical white wood, Foundations of Tropical Forest Biology: Classic Papers with Commentaries. The University of Chicago Press, Chicago, USA, p. 21-30.

13. Odugbemi 0 (2008) A textbook of medicinal plants from Nigeria, University of Lagos press, Nigeria, p.14.

14. Ilesanmi OB, MT Olaleye, Akinmoladun AC, Alawode TT (2016) HPLC quantitation of phenolic content and assessment of methanolic extract of Antiaris Africana for toxicological study. Africana journal of Biotechnology 15(9): 320-330.

15. Maharaj DS, RB Walker, BD Glass, S Daya (2003) 6-Hydroxymelatonin protects against cyanide induced oxidative stress in rat brain homogenates. J Chem Neuroanat 26(2): 103-107.

16. Pennington R (1961) Biochemistry of dystrophic muscle: mitochondrial succinate tetrazolium reductase and adenosine triphosphatase. Biochemistry Journal 80(3): 649-654.

17. Jollow D, L Mitchell, N Zampaglione, J Gillete (1974) Bromobenzene induced liver necrosis: protective role of glutathione and evidence for 3, 4-bromobenzenoxide as the hepatotoxic metabolite. Pharmacology 11(3): 151-169.

18. Okhawa H, N Ohishi, K Yagi (1979) Assay for lipid peroxide in animal tissues by Thiobarbituric acid reaction. Annual Review of Biochemistry 95(2): 351-352.

19. Adam Vizi V, M Seregi (1982) Receptor dependent stimulatory effect of noradrenaline on $\mathrm{Na}+\mathrm{K}+$ ATPase in rat brain homogenate. Role of lipid peroxidation. Biochem Pharmacol 31(13): 2231-2236.

20. Floor E, MG Wetzel (1998) Increased protein oxidation in human substantia nigra pars compacta in comparison with basal ganglia and prefrontal cortex measured with an improved dinitrophenylhydrazine assay. Journal of Neurochemistry 70(1): 268-275.

21. Holt A, DF Sharman, GB Baker, MM Palcic (1997) A continuous spectrophotometric assay for monoamine oxidase and related enzymes in tissue homogenates. Annual review of Biochemistry. 244(2): 384-392.

22. Chaudhary S, S Parvez (2012) An invitro approach to assess the 
neurotoxicity of valproic acid-induced oxidative stress in cerebellum and cerebral cortex of young rats. Neuroscience 225: 258-268.

23. Akinmoladun AC, OO Crown, OB Ojo, MT Olaleye, EO Farombi (2014) Antidenaturation and antioxidative properties of phytochemical components from Spondias mombin. Academic journal 8(5): 101-110.

24. Kuete V, B Vouffo, AT Mbaveng, EY Vouffo, RM Siagat, et al. (2009) Evaluation of Antiaris africana methanol extract and compounds for antioxidant and antitumor activities. Pharmaceutical Biology/ International Journal of Pharmacognosy 47(11): 1042-1049.

25. Banso A, Mann (2008) Evaluation of antibacterial properties of flavonoid fraction from Antiaris africana. Journal of Applied Biosciences 12: 665670.

26. Anacharis BS, Soares AA, Luiza de Oliveira A Comar JF, Peralta RM, Bracht A (2014) Effects of Treating Old Rats with an Aqueous Agaricus blazei Extract on Oxidative and Functional Parameters of the Brain Tissue and Brain Mitochondria. Oxidative Medicine and Cellular Longevity 563179: (1-13).

27. Ajith TA, NP Sudheesh, D Roshny, G Abishek, KK Janardhanan (2009) Effect of Ganoderma lucidum on the activities of mitochondrial dehydrogenases and complex I and II of electron transport chain in the brain of aged rats. Experimental Gerontology 44(3): 219-223.

28. Gautier NMV, JDM Mihoub, G Lelandais, P Bouloc, A Landoulsi, et al (2015) Fermentation and alternative respiration compensate for NADH dehydrogenase deficiency in a prokaryotic model of DJ-1-associated Parkinsonism. Microbiology 161(11): 2220-2231.

29. Kuznetsov AV, S Schneeberger, R Seiler, G Brandacher, W Mark, et al. (2004) Mitochondrial defects and heterogeneous cytochrome c release after cardiac cold ischemia and reperfusion. Am J Physiol Heart Circ Physiol 286(5): 1633-1641.

ISSN: 2574-1241

DOI: 10.26717/BJSTR.2019.13.002371

Omotayo B Ilesanmi. Biomed J Sci \& Tech Res

This work is licensed under Creative Commons Attribution 4.0 License

Submission Link: https://biomedres.us/submit-manuscript.php
30. Mandemakers VA, B Morais De Strooper A (2007) Cell biological perspective on mitochondrial dysfunction in Parkinson disease and other neurodegenerative diseases. J Cell Sci 1209(10): 1707-1716.

31. Aoyama K, M Watabe, T Nakaki (2008) Regulation of neuronal glutathione synthesis. Journal of Pharmacological Science 108(3): $227-$ 238.

32. Abdel Salam MEO, Youness ER, Ahmed NA, El Toumy SA, MAA Souleman, et al. (2017) Bougainvillea spectabilis flowers extract protects against the rotenone-induced toxicity. Asian Pacific Journal of Tropical Medicine 10(5): 478-490.

33. Muralidhara Gokul K (2014) Oral supplements of aqueous extract of tomato seeds alleviate motor abnormality, oxidative impairments and neurotoxicity induced by rotenone in mice: relevance to Parkinson's disease. Neurochem Res 39(7): 1382-1394.

34. De Virgilio A, Greco A, Fabbrini G, Inghilleri M, Rizzo MI, et al. (2016) Parkinson's disease: autoimmunity and neuroinflammation. Autoimmun Rev 15(10): 1005-1011.

35. Niedzielska E, I Smaga, M Gawlik, A Moniczewski, P Stankowicz, et al. (2016) Oxidative Stress in Neurodegenerative Diseases. Mol Neurobiol 53(6): 4094-4125.

36. Hirayama M, Goto S, Nakamura T, Mizutani Y, Suzuki J, et al. (2014) Oxdative stress maker (urinary 8-hydroxy-2'-deoxyguanosine) was modified by treatment of various Parkinson's drug. Mov Disord 29(1): 140

37. Popa Wagner A, S Mitran, S Sivanesan, E Chang, A Buga (2013) ROS and brain diseases: the good, the bad, and the ugly. Oxidative Med Cell Longevity 1: 963520.

\begin{tabular}{ll} 
BIOMEDICAL & Assets of Publishing with us \\
RESEARCHES & - Global archiving of articles \\
& - Immediate, unrestricted online access \\
\hline ISSN: 2574-1241 & - Rigorous Peer Review Process \\
&
\end{tabular}

Cite this article: Omotayo B I, Rofiat A, Alawode T T, Kayode C K, Temitope T O. et al., Alteration of NADH Succinate Dehydrogenase Activity and 